\title{
HUBUNGAN TRADISI PENGHANGATAN ARANG DAN KONDISI FISIK RUMAH DENGAN KEJADIAN ISPA PADA IBU NIFAS DI DESA BERAMPU KECAMATAN BERAMPU KABUPATEN DAIRI TAHUN 2020
}

\section{FITHRI HANDAYANI LUBIS ${ }^{1}$, JELI KRISYANI SIHOMBING²}

FAKULTAS KESEHATAN MASYARAKAT INSTITUT KESEHATAN DELI HUSADA JLN. BESAR NO. 77 DELI TUA KAB. DELI SERDANG - SUMATERA UTARA 20355 e-mail :fithri.handa@gmail.com, jkrisyani@gmail.com

DOI : https://doi.org/10.35451/jkg.v4i1.617

\begin{abstract}
Charcoal warming tradition is believed to help the recovery process in postpartum mothers. The purpose of this study was to determine the relationship between charcoal warming traditions and physical conditions of the house with the incidence of acute respiratory infections in postpartum mothers. The method of reseaech used the analytic case control approach. The population of this research was 50 mothers who had history of acute respiratory infections in Berampu village and the control sample was 50 people. The technique of the sample of this research is probability sampling. The Statistical analysis used bivariate analysis with chi square test and multivariate analysis with logistic regression test. The results of the bivariate analysis showed a relationship between the Charcoal Warming Tradition, $p$ value $=0.002$, between maternal parity, $p$ value $=0.043$, between the physical conditions of the house, $p=0.027$, and the incidence of acute respiratory infections. The results of the multivariate analysis show that there is an influence between the Charcoal Warming Tradition (Exp B: 3,626), Mother Parity (Exp B: 2,517) and the Physical Condition of the House (Exp B: 2,354 ) on the incidence of acute respiratory infections in post- partum mothers in Berampu Village, District, Dairi Regency in 2020 The Suggestions for researchers Furthermore, this research is used as reference material regarding acute respiratory infections in order to carry out the proper management of acute respiratory infections. or Respondents to replace the warming tradition by using blankets. For public health center Developing health promotion for postpartum education.
\end{abstract}

Keywords: tradition, parity, physical condition of the house, acute respiratory infections.

\section{PENDAhUlUAN}

AKI adalah jumlah kematian ibu selama masa kehamilan, persalinan dan nifas yang disebabkan oleh kehamilan, persalinan, dan nifas atau pengelolaannya tetapi bukan karena sebab-sebab lain seperti kecelakaan atau terjatuh di setiap 100.000 kelahiran hidup (WHO, 2019). Timbulnya masalah kejadian ispa tersebut, diduga tidak lepas dari berbagai faktor antara lain penghangatan arang pada ibu nifas yang menghasilkan asap mengganggu 
sistem pernafasan ibu (Anggraini, 2015). Faktor paritas ibu yang dihitung dari berapa kali ibu menggunakan tradisi penghangatan arang selama melahirkan dan faktor kondisi fisik rumah yang tidak memenuhi syarat faktor lain dari permasalahan kejadian ispa, adalah masyarakat masih cenderung menganggap bahwa tradisi penghangatan dipercayai dapat mempercepat pemulihan pasca melahirkan ibu nifas (Agungnisa, Adhasari, 2017).

\section{METODE}

Metode penelitian ini menggunakan analitik dengan rancangan penelitian yang digunakan case control merupakan penelitian jenis analitik observasional yang dilakukan dengan cara membandingkan antara kelompok kasus dan kelompok kontrol berdasarkan status paparannya. Hal tersebut bergerak dari akibat (penyakit) ke sebab (paparan) (Notoatmodjo, S. 2018). Populasi dalam penelitian ini adalah ibu yang memiliki riwayat ISPA di Desa Berampu dengan jumlah sampel kasus sebanyak 50 orang dan sampel kontrol 50 orang. teknik menentukan sampel penelitian ini adalah "probability sampling yaitu menggunakan simple random sampling. Analisis statistik yang digunakan adalah analisis bivariat dengan uji chi square dan analisis multivariat dengan uji regresi logistik.

\section{HASIL DAN PEMBAHASAN}

Tabel 1.

Hasil Tabulasi Silang Tradisi Penghangatan Arang Dengan Kejadian ISPA

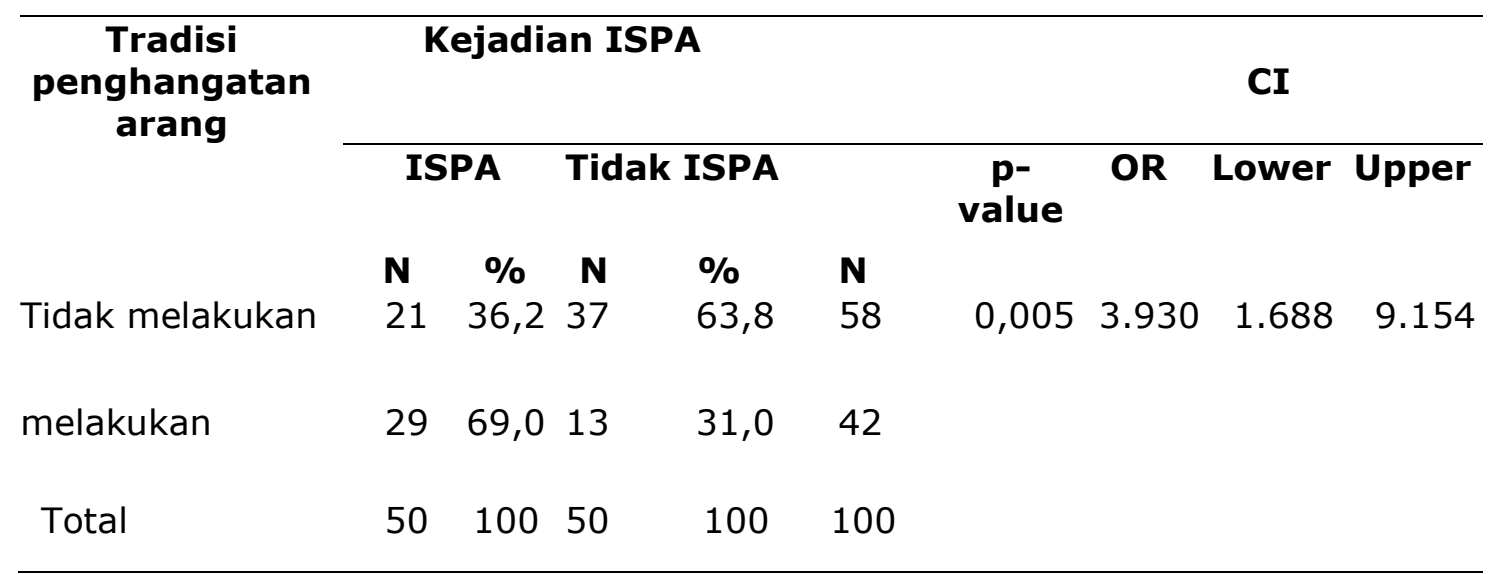

Bahwa kejadian ISPA pada ibu lebih banyak terjadi pada kelompok kasus dibanding kelompok kontrol, ibu yang melakukan tradisi penghangatan menggunakan arang sebanyak 29 $(69,0 \%)$ responden sedangkan pada kelompok kontrol hanya 13 (44.0\%) responden. Berdasarkan hasil uji ChiSquare yang telah dilakukan dilihat (continuity correction) dengan $\mathrm{P}$-Value $0,005<0,05$ yang artinya ada hubungan antara tradisi penghangatan menggunakan arang dengan kejadian
ISPA pada ibu di Puskesmas Berampu. Dengan nilai OR sebesar 3.930>1 yang artinya ibu yang melakukan tradisi penghangatan berisiko 3.930 kali dibandingkan dengan ibu yang tidak melakukan Tradisi penghangatan penggunaan arang selama masa nifas.

Asap dari pembakaran kayu, arang dan bahan organik lain mengandung berbagai zat kimia, yakni partikel halus (particulate matter/PM) dan gas. Gas karbon monoksida, sulfur dioksida, nitrogen oksida dan ozon merupakan 
gas yang paling dominan yang terdapat dalam kandungan asap (Fortyanus Gilbert, 2019). Secara umum bahan pencemar senyawa kimia nitrogen oksida, sulfur dioksida, karbon monoksida, ozon dan partikulat di udara dapat menyebabkan gangguan kesehatan pada manusia seperti gangguan pernapasan, penyakit asma dan bronchitis, luka mata, mata terasa pedih dan berair, pusing kepala, kelelahan, batuk-batuk serta dapat menimbulkan gangguan pada sistem syaraf (Dewi, Rosmala. 2020).

Tabel 2.

Hasil Tabulasi Silang Paritas ibu Dengan Kejadian ISPA

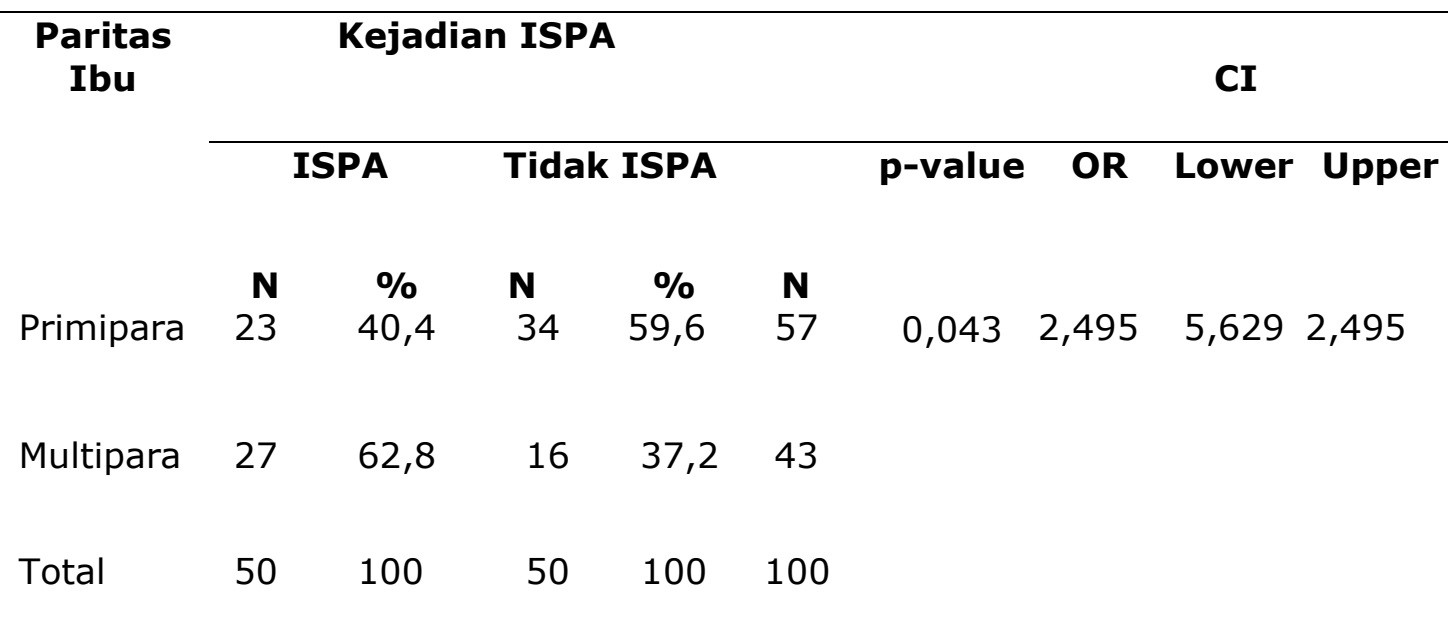

Bahwa kejadian ISPA pada ibu lebih banyak terjadi pada kelompok kasus dibanding kelompok kontrol, ibu yang sudah melahirkan lebih dari 2-4 anak memiliki resiko tinggi terkena kejadian ISPA sebanyak 27 (62,8\%) responden sedangkan pada kelompok kontrol hanya $16(37,2 \%)$ responden. Berdasarkan hasil uji Chi-Square yang telah dilakukan dilihat (continuity correction) dengan P-Value 0,043<0,05 yang artinya ada hubungan antara Paritas ibu dengan kejadian ISPA pada ibu di Desa Berampu. Dengan nilai OR sebesar 2,495>1 yang artinya ibu yang melahirkan lebih dari 2-4 anak lebih berisiko 2,495 kali terkena ISPA dibandingkan dengan ibu yang melahirkan hanya sekali.

Penelitian ini sejalan dengan penelitian yang dilakukan oleh Karlina, Syamsudin (2017). yang mengatakan bahwa disimpulkan ada hubungan bahwa riwayat melahirkan dari ibu yang terkena penyakit ISPA dengan jumlah keseluruhan 100 responden sesuai dengan data yang diambil di tempat penelitan yaitu pernah melahirkan 1 kali (Paripara) sebanyak 36 responden, peresentasi 3,6 \%. Pernah melahirkan 2-4 kali (Multipara) sebanyak 64 responden dengan presentase $64,0 \%$. Paritas ibu mempengaruhi kejadian Ispa pada ibu, Karena semakin sering ibu terpapar asap dari hasil pembakaran arang maka akan semakin tinggi resiko terkena kejadian ISPA, banyak masyarakat yang menggunakan tradisi penghangatan arang sebanyak berapa kali ibu melahirkan anak. 
Tabel 3.

Hasil Tabulasi Silang kondisi fisik rumah Dengan kejadian ISPA

\begin{tabular}{|c|c|c|c|c|c|c|c|c|c|}
\hline \multirow{3}{*}{$\begin{array}{c}\text { Kondisi } \\
\text { fisik rumah }\end{array}$} & \multicolumn{6}{|c|}{ Kejadian ISPA } & \multirow{2}{*}{\multicolumn{3}{|c|}{ CI }} \\
\hline & & & & & & & & & \\
\hline & $\begin{array}{c}\text { ISP } \\
\text { A }\end{array}$ & & $\begin{array}{l}\text { Tidal } \\
\text { ISPA }\end{array}$ & & & $\begin{array}{c}\text { p- } \\
\text { value }\end{array}$ & OR & Lower & Upper \\
\hline & $\mathbf{N}$ & $\%$ & $\mathbf{N}$ & $\%$ & $\mathbf{N}$ & & & & \\
\hline $\begin{array}{l}\text { Memenuhi } \\
\text { syarat }\end{array}$ & 22 & 39,9 & 34 & 60,7 & 56 & 0,027 & 1,495 & 1,101 & 4,629 \\
\hline $\begin{array}{l}\text { Tidak } \\
\text { memenuhi } \\
\text { syarat }\end{array}$ & 28 & 63,6 & 16 & 37,2 & 44 & & & & \\
\hline Total & 50 & 100 & 50 & 100 & 100 & & & & \\
\hline
\end{tabular}

Dari 100 responden yang kondisi fisik rrumahnya pada kelompok kasus yang tidak memenuhi syarat terdapat 28 $(63,6 \%)$ ibu yang mengalami kejadian ISPA, sedangkan pada kelompok kontrol hanya 16 responden $(37,2 \%)$. Berdasarkan hasil uji Chi-Square yang telah dilakukan dilihat koreksi (continuity correction) dengan P-Value 0,027 yang artinya ada hubungan antara kondisi fisik rumah dengan kejadian ISPA pada ibu di Puskesmas Berampu. Dengan nilai OR sebesar $1,495>1$ yang artinya ibu yang tinggal dirumah dengan kondisi fisik rumah yang tidak memenuhi syarat lebih berisiko 1,495kali dibandingkan dengan ibu yang tinggal dirumah dengan kondisi fisik rumah yang memenuhi syarat.

Faktor-faktor kondisi fisik rumah mempengaruhi status derajat kesehatan bagi masyarakat beberapa faktor kondisi fisik rumah yaitu Luas ventilasi rumah, kepemilikan lubang asap, jenis lantai, jenis dinding, dan kepadatan penghuni yang diberi bobot nilai 20 setiap poin apabila faktor kondisi fisik rumah memenuhi syarat dengan skor $<65$ tidak memenuhi syarat dan $>65$ memenuhi syarat rumah sehat (Sinambela juita, dkk, 2019). Kondisi fisik rumah yang tidak memenuhi syarat pada suatu ruangan makin membahayakan kesehatan atau kehidupan, jika dalam ruangan tersebut terjadi pencemaran oleh bakteri seperti oleh penderita infeksi saluran pernafasan atau berbagai zat kimia organik atau anorganik (Sri, dkk, 2017). Kondisi fisik rumah yang memenuhi syarat berfungsi juga untuk membebaskan udara ruangan dari bakteri-bakteri, terutama bakteri patogen seperti ISPA, karena di situ selalu terjadi aliran udara yang terus menerus. Bakteri yang terbawa oleh udara akan selalu mengalir (Yunita, Juni, 2015). Selain itu, kondisi fisik rumah tidak memenuhi syarat kesehatan akan mengakibatkan terhalangnya proses pertukaran udara dan sinar matahari yang masuk ke dalam rumah, akibatnya kuman yang ada di dalam rumah tidak dapat keluar dan ikut terhisap bersama udara pernafasan. 
Tabel 4.

Hasil Analisis Uji Regresi Berganda Binary Pengaruh Tradisi Penghangatan Arang, Paritas Ibu Dan Kondisi Fisik Terhadap Kejadian ISPA Pada Ibu Nifas Di Desa Berampu Kecamatan Berampu Kabupaten Dairi Tahun 2020.

\begin{tabular}{lcccccccc}
\hline \multicolumn{1}{c}{ B } & \multicolumn{9}{c}{$95 \%$ C.I.for EXP(B) } & & & \\
& & S.E & Wald Df & Sig. Exp(B) & $\begin{array}{c}\text { Lo- } \\
\text { wer }\end{array}$ & $\begin{array}{l}\text { Up- } \\
\text { per }\end{array}$ \\
\hline $\begin{array}{l}\text { Tradisi } \\
\begin{array}{l}\text { Penghangatan } \\
\text { arang }\end{array}\end{array}$ & 1.288 & .456 & 7.987 & 1 & .005 & 3.626 & 1.484 & 8.861 \\
$\begin{array}{l}\text { Paritas ibu } \\
\text { Kondisi fisik }\end{array}$ & .923 & .451 & 4.188 & 1 & .041 & 2.517 & 1.040 & 6.091 \\
$\begin{array}{l}\text { rumah } \\
\text { Constant }\end{array}$ & .856 & .447 & 3.667 & 1 & .055 & 2.354 & .980 & 5.655 \\
& -1.30 & .397 & 10.785 & 1 & .001 & .271 & &
\end{tabular}

Berdasarkan tabel 3.4 hasil penelitian mengenai pengaruh variabel independen Tradisi penghangatan arang, paritas ibu dan kondisi fisik adalah pengaruh terhadap kejadian ISPA pada ibu nifas di Desa Berampu Kecamatan Berampu Kabupaten Dairi tahun 2020 dengan menggunakan uji regresi berganda binary dengan metode Enter. Hal ini menunjukkan bahwa pengaruh Tradisi penghangatan arang 3.626 kali lebih dominan menjadi penyebab kejadian ISPA pada ibu nifas di Desa Berampu Kecamatan Berampu Kabupaten Dairi tahun 2020 dengan nilai signifikan $0.005 \quad(\mathrm{Cl}: 95 \%, 1.484 \quad-$ 8.861).

Penelitian ini sejalan dengan penelitian yang dilakukan oleh Mega, dkk (2018). Asap dari pembakaran kayu, arang dan bahan organik lain mengandung berbagai zat kimia, yakni partikel halus (particulate matter/PM) dan gas. Gas karbon monoksida, sulfur dioksida, nitrogen oksida dan ozon merupakan gas yang paling dominan yang terdapat dalam kandungan asap.Secara umum bahan pencemar senyawa kimia nitrogen oksida, sulfur dioksida, karbon monoksida, ozon dan partikulat di udara dapat menyebabkan gangguan kesehatan pada manusia seperti gangguan pernapasan, penyakit asma dan bronchitis, luka mata, mata terasa pedih dan berair, pusing kepala, kelelahan, batuk-batuk serta dapat menimbulkan gangguan pada sistem syaraf.

Berdasarkan penjelasan diatas dapat diketahui bahwa praktik tradisi penghangatan arang merupakan perilaku berisiko yang masih tetap dijalankan oleh masyarakat. Tenaga kesehatan perlu memberikan perhatian khusus dan memantau pelaksanaan tradisi penghangatan arang yang masih dilakukan oleh masyarakat. 


\section{KESIMPULAN DAN SARAN}

\section{Kesimpulan}

Setelah dilakukan penelitian tentang Tradisi marapi merupakan salah satu tradisi yang masih dilakukan oleh masyarakat di Desa Berampu. Ada hubungan yang signifikan antara Tradisi Penghangatan Arangparitas ibu dan kondisi fisik rumah dengan Kejadian ISPA, dari beberapa variabel setelah di uji regresi berganda binary dengan metode Enter menunjukkan bahwa pengaruh Tradisi penghangatan arang 3.626 kali lebih dominan menjadi penyebab kejadian ISPA pada ibu nifas di Desa Berampu Kecamatan Berampu Kabupaten Dairi tahun 2020 .

\section{Saran}

Berdasarkan hasil pembahasan dan kesimpulan yang telah dibuat maka dapat diberikan saran-saran sebagai berikut:

\section{Bagi Peneliti Selanjutnya}

Sebagai bahan refrensi bagi penelitian lain yang ingin mendalami ataupun ingin mempertegas hasil dari penelitian ini.

\section{Bagi Responden}

Perawatan masa nifas untuk ibu dan bayi diharapkan dapat dilakukan dengan cara yang lebih sehat. Misalnya untuk menghangatkan ibu dan bayi bisa menggunakan selimut

\section{Bagi Puskesmas}

Mengembangkan promosi kesehatan dan memberikan edukasi tentang perawatan ibu nifas.

\section{DAFTAR PUSTAKA}

$$
\begin{array}{r}
\text { Agungnisa, Adhasari. (2017), } \\
\text { Sanitasi Fisik Rumah } \\
\text { Berpengaruh Terhadap Kejadian } \\
\text { Ispa Pada Balita Di Desa Kalianget }
\end{array}
$$

Timur. Vol. 11 No. 1 Januari 2019 (1-9).

Anggraini, (2015) Asuhan Kebidanan Masa Nifas. Yogyakarta: Pustaka Rihama;.Cultural Factors In Treatment In The Postpartum Mother .Jurnal Ilmu Keperawatan (2017) 5:1

Dewi, Rosmala. (2020). Tradisi Marapi dan Hubungannya dengan Kesehatan Ibu dan Bayi (Studi Fenomenologi di Desa Manunggang Jae). Fakultas Kesehatan Masyarakat. Universitas Sumatera Utara

Fortyanus Gilbert, (2019) Tradisi Manganggap Pada Komunitas Batak Di Bengkong Indah Kota Batam ( Studi Tentang Perubahan Sosial). JOM FISIP Vol. 6

Karlina, Syamsudin. (2017). Hubungan Tingkat Pendidikan Ibu Balita, Paritas Dan Status Ekonomi Keluarga Dengan Kejadian Penyakit Ispa Di Puskesmas Kalumata Tahun 2017. Mahasiswa Peminatan Akk. Fakultas Ilmu Kesehatan. Universitas Muhammadiyah Maluku Utara.

Mega, dkk. (2018). Hubungan Antara Kondisi Fisik Rumah Dengan Kejadian Ispa Pada Balita Di Desa Kalinaun Kabupaten Minahasa Utara. Fakultas Kesehatan Masyarakat Universitas Sam Ratulangi Manado.

Notoatmodjo, S. 2018. Metodologi Penelitian Kesehatan. Jakarta: Renika Cipta

Sinambela juita, dkk. (2019) Postpartum Maternal Care Tradition Among Timor Tribe In Timor Tengah Selatan Regency Nusa Tenggara Timur Province. International Journal of Public Health and Clinical Sciences e-ISSN : 2289-7577. Vol. 6:No. 6 November/December 2019

Sri, dkk. (2017). Faktor Budaya Dalam Perawatan Ibu Nifas 
https://ejournal.medistra.ac.id/index.php/JKG

Received: 12 April 2021 :: Accepted: 02 Oktober 2021 :: Published: 31 Oktober 2021

World Health Organization. (2019).

Maternal Mortality. Diakses dari

https://www.who.int/en/news

room/fact-sheets/detail/maternal-

mortality

Yunita, Juni. (2015). Pengobatan

Tradisional Gayo Untuk Ibu

Nifas.Hal 114. 